\title{
Future outlook and financial strain: Testing the personal agency and latent deprivation models of unemployment and well-being
}

\author{
Authors: Peter A Creed and Jan Klisch \\ Griffith University - Gold Coast, Australia
}
Contact: Associate Professor Peter A Creed
School of Applied Psychology
Griffith University
PMB 50 GCMC
Gold Coast 9726
Australia

Telephone: +61755528810

Facsimile:+61 755528291

Email: p.creed@griffith.edu.au

Keywords: Agency Restriction Model, Latent Deprivation Model, financial strain, future orientation, social support, collective purpose, time structure, activity, status, unemployment, principal income earner 


\title{
Future outlook and financial strain: Testing the personal agency and latent deprivation models of unemployment and well-being
}

\begin{abstract}
Two hundred and thirty-nine unemployed adults were administered scales tapping wellbeing, financial strain, future orientation, the latent benefits of employment, neuroticism, length of unemployment and whether the person was the principal income earner in the household. First, the study tested the relative contributions of the Latent Deprivation Model and the Agency Restriction Model in predicting psychological well-being of unemployed people. Second, the study tested whether financial strain interacted with future orientation to predict well-being, or whether financial strain was mediated by future orientation. The study found support for the Agency Restriction Model over the Latent Deprivation Model, but concluded that examining internal personal agency processes in the context of the individual's temperament and situation is needed to explain the decline in well-being associated with unemployment. No interaction effects were identified and future orientation did not mediate the influence of financial strain. The contextual variable of the unemployed person being a principal income earner influenced well-being directly, the latent benefit of social support influenced well-being indirectly via future orientation, length of unemployment influenced well-being indirectly through negative future orientation, whereas the personality variable of neuroticism had a direct effect on well-being and an indirect effect via future orientation. Practical implications are also indicated.
\end{abstract}


Unemployment remains one of the most serious and troublesome problems facing society generally (Milne \& Ryle, 1996). In Australia, unemployment is a major social issue, with the current unemployment rate of between $6-7 \%$ of the working population (ABS, 2003), although some estimates are that there are large numbers of "hidden unemployed" who place this percentage much higher (Spiers, 1991). Economic predictions indicate that unemployment rates will continue to remain high (Dawkins, 1996), suggesting that a substantial number of people will experience unemployment at some level during their working life.

Being unemployed is typically associated with lowered levels of psychological wellbeing (Murphy \& Athanasou, 1999). For example, when the unemployed are compared with those in employment, the unemployed report greater psychological distress (Creed \& Muller, submitted), lower self-esteem (Muller, Hicks, \& Winocur, 1993) and higher levels of depression (Waters \& Moore, 2002). Further, longitudinal studies have demonstrated that unemployment is largely causally related to a decline in well-being, rather than poor well-being being associated with less healthy people drifting into unemployment (Creed, 1999; Winefield, Tiggemann, Winefield, \& Goldney, 1993).

Two theoretical perspectives have dominated the research on the effects of unemployment on psychological well-being, the Latent Deprivation Model (Jahoda, 1981) and the Agency Restriction Model (Fryer, 1986; Fryer \& Payne, 1986). Jahoda argued that paid work provides both manifest benefits (linked to income) and latent benefits (associated with meeting psychological needs). Individuals are drawn to work for financial reasons, but while at work also benefit from five main unintentional, or latent, benefits, that of having a time structure, an enlarged social contact, common goals, an 
acceptable status and a collective purpose. In this model, when a person becomes unemployed, the decline in well-being is seen to be associated with a loss of these latent benefits, rather than the deprivation of the manifest benefits.

Evidence for this model has come from studies that have examined the latent benefits of employment, both singly and in concert, and suggested that the unemployed have less access to these benefits, and that less access is associated with poorer well-being. As an example, Jahoda (1984, p.22) argued that most telling on psychological well-being was “...the enforced destruction of an habitual time structure for the waking day with the onset of unemployment". Related to this, unemployed people have been shown to have less time structure in their lives and use their time less purposefully than employed people (Jackson, 1999), and that low levels of time structure have been associated with poorer levels of well-being (Evans \& Haworth, 1991). Jahoda also argued that the unemployed experience an enforced narrowing of social contacts and an impoverishment of social experience. While the individual may not necessarily enjoy or like the social contacts that employment enforces, they are undeniably "a source for enlarging his (sic) social horizon" (Jahoda, 1982, p.25). In relation to this latent benefit, unemployed people have been found to be involved in fewer social activities than those not unemployed (Underlid, 1996), and less social contact has been associated with lower well-being (Haworth \& Ducker, 1991) and higher levels of depression (Bolton \& Oatley, 1987).

One study has directly tested Jahoda's hypothesis by measuring both the manifest and latent benefits of work together (Creed \& Macintyre, 2001). This study demonstrated that all latent benefits, as well as the manifest benefit (operationalised as financial strain), were significantly and meaningfully associated with psychological distress in an 
unemployed sample, and together were able to account for a sizable proportion (52\%) of the variance in psychological distress. The above findings generally support the notion that the unemployed have less access to the latent benefits than their employed counterparts, and that the level of access is related to well-being.

The alternative proposal to the Latent Deprivation Model is the Agency Restriction Model developed by Fryer (1986; Fryer \& Payne, 1986). Whereas the Latent Deprivation Model stresses the importance of the latent benefits of employment over financial benefits, the Agency Restriction Model, while acknowledging the latent benefits, places much more stress on the loss of the financial aspects of employment. Fryer (1995) argued that there are two important factors that account for the observed decline in psychological well-being of the unemployed. First, unemployment "generally results in corrosive ...poverty", and second, unemployment "cuts the unemployed person off from any future, making looking forward and planning very difficult" (p. 270). These two factors are important because they restrict or frustrate personal agency, thus making it difficult for the individual to plan a personally satisfying lifestyle that is required for growth and the maintenance of well-being.

Many studies have demonstrated that financial hardship is one of the most difficult and consistent problems that people experience during unemployment (cf. Feather, 1990; Viinamaki, Koskela, Niskanen, \& Arnkill, 1993). Jackson (1999), for example, found that unemployed young people reported more financial stress than either employed or student samples, while Kokko and Pulkkinen (1997), when comparing unemployed with employed adults, found that the unemployed experienced more financial hardship and were more distressed. Whelan (1992), who examined a large-scale Irish national 
database, concluded that poverty, construed as both subjective experiences of financial strain and objective material deprivation, played a substantial role in mediating the effects of unemployment for both the individual involved and the person's family.

Despite evidence demonstrating the important effects of poverty on the unemployed, using both direct and proxy measures, very few studies have examined the effects of future orientation on the psychological well-being of unemployed people. Future orientation can be defined as the construction of prospective self-representations in terms of hopes and fears, and is seen to provide a basis for anticipating future events, setting goals, planning, exploring options, making commitments and subsequently guiding a developmental course (Nuri, 1991; Seginer, 2000). One study that tested this aspect of Fryer's model (Fryer \& McKenna, 1987) used semi-structured interviews to compare two small groups of unemployed men who had been laid off from their factory jobs. One group had been made temporarily redundant, while the other had been permanently laid off. Contrary to the predictions of the Latent Deprivation Model, both groups were not equally deprived of the latent benefits, and were not equally distressed. Those who were temporarily laid off had arranged active and productive lives and appeared to be psychologically healthy, which was not the case for the indefinitely retrenched group. The authors concluded that the temporarily laid off men were able to obtain the latent benefits outside of the work environment, were more optimistic about the future, and would eventually return to work for the manifest, rather than the latent benefits of employment.

In other areas, a negative future orientation has been shown to be associated with poor psychological well-being. For example, effective functioning and well-being are 
associated with striving to achieve self-relevant goals (Banaji \& Prentice, 1994; Cantor \& Fleeson, 1991), and commitments such as marriage, religion and career are associated with overall life satisfaction and well-being (Batson \& Ventis, 1982). Adolescents raised in high risk environments who maintain a positive future orientation are less likely to experience psychological and social problems later in life than their less optimistic peers (McCabe \& Barnett, 2000). Patients suffering from chronic pain who perceive the future more negatively experience more psychological distress than those who perceive the future positively (Hellstrom, Jansson, \& Carlsson, 2000), while patients with negative future orientations are more likely to have higher levels of depression (Hawkins, Hawkins, Sabatino, \& Ley, 1998.

The above studies indicate support for a negative future orientation having a direct effect on reducing psychological well-being. However, Fryer (1995) argued on the one hand that, for the unemployed, the experiences of poverty and having a negative future orientation "coalesce in the notion of economic insecurity" (p. 271). This implies that poverty and a negative view of the future may interact with one another to reduce psychological well-being. On the other hand, he argued that "... relative poverty becomes translated into tortuous budgeting strategies, (and) painful prioritizing of ...needs" (p. 271). This implies that poverty may influence the unemployed person's view of the future, as well as poverty directly influencing well-being. This latter case refers to the view of the future mediating the effect of poverty on well-being.

On the basis of the above review, the present study will expand on what has already been found in relation to the psychological health of unemployed people. First, the study will test the relative direct contributions of the latent benefits of employment (Latent 
Deprivation Model) and the manifest benefits of employment and perceived future orientation (Agency Restriction Model) in predicting the psychological well-being of unemployed people. Second, the study will test whether the manifest benefits of employment (operationalised in this study as financial strain) interact with perceived future orientation to influence well-being. And third, the study will test whether financial strain influences psychological well-being via future orientation, as well as directly, that is, test whether perceived future orientation acts as a mediating variable between financial strain and well-being. Two important variables have been identified that moderate the experience of unemployment for the individual. Theses are whether the person is the principal income earner in the household or not (Creed \& Bartrum, submitted), and the neurotic disposition of the person (Creed, Muller \& Machin, 2001; Payne, 1988). Both of these variables will be measured and controlled for in the present study.

\section{Method}

\section{Participants}

A total of 248 unemployed adults were surveyed. A list-wise deletion procedure indicated that nine participants did not adequately complete all components of the survey. This left 239 in the sample, which then comprised $133(55.60 \%)$ females and 106 $(44.40 \%)$ males, whose mean age was 30.43 years $($ Range $=16-59.75$ years, $S D=11.40)$, and who had been unemployed on average for 1.80 years $($ Range $=.10-19.00 ; S D=$ 2.98). All participants were registered as being unemployed with the national employment agency in the south-eastern part of Queensland, Australia. 


\section{Measures}

Psychological Distress: The 12-item version of the General Health Questionnaire (GHQ; Goldberg, 1972) was used as a measure of global distress. This scale has been widely used in occupational settings. It taps two major areas of distress, that of the inability to carry out normal daily functions and the appearance of new phenomenon of a distressing nature (Goldberg \& Williams, 1988). Respondents are asked to indicate how they have felt recently across a range of variables, including depression, anxiety, selfesteem and cognitive processing. A sample item is, "Have you recently been feeling unhappy and depressed?" Responses are scored on a 4-point Likert scale from "0" (not at all) to " 3 " (much more than usual). Higher sores on the scale indicate more psychological distress. Goldberg and Williams reported sound psychometric properties for the GHQ.

Latent Benefits of Employment: Five 8-item subscales from the Latent and Manifest Benefits of Employment scale (LAMB; Muller, Creed, Waters, \& Machin, 2000) were used to measure the latent benefits of time structure, social support, collective purpose, status, and activity. Respondents were asked to indicate the strength of their agreement on a 7-point scale to bipolar statements, such as "Time usually drags for me/Time rarely drags for me" (Time Structure, TS), "I regularly do things with other people/I rarely do things with other people" (Social Support, SS), "I usually feel a part of the community/I rarely feel a part of the community" (Collective Purpose, CP), "What I do is important/What I do is not important" (Status, ST), and "I usually have a lot of things to do/I rarely have a lot of things to do" (Activity, AC). Higher scores indicate more access to the respective benefits. Muller et al. report adequate initial psychometric properties. 
Manifest Benefits of Employment: The 8-item manifest benefit subscale (Financial Strain, FS) from the LAMB scale (Muller et al. 2000) was used to measure this construct. Respondents were asked to indicate the strength of their agreement on a 7-point scale to bipolar statements, such as "I can usually live on the money I receive/I usually have trouble living on the money I receive". Higher scores indicated more financial distress. Muller et al. provide adequate initial psychometric properties

Perceived Future Orientation: The 20-item Beck Hopelessness Scale (BHS; Beck, Weissman, Lester, \& Trexler, 1974) was used to assess participants' perceived future orientation. The BHS consists of true and false statements that assess the extent of positive and negative expectancies about the immediate and long-term future. Each of the statements is scored "1" or " 2 ", with nine keyed as false and 11 keyed as true, to indicate the endorsement of pessimism or optimism about the future. The items are summed to yield a total score with higher scores indicating greater hopelessness. A sample statement is, "My future seems dark to me". Although the instrument was developed to measure attitudes about the future for clinical patients, it has been used with adolescent and adult normal populations, and is recommended as appropriate for respondents over the age of seventeen years (Green, 1981). Originally, the psychometric properties of the scale were derived from clinical samples, but more recently have been examined in normal populations, with two factors, one reflecting negatively worded items about the future and one reflecting positively worded items about the future, being identified (Steed, 2001).

Neuroticism: The 12-item Neuroticism scale from the short version of the Eysenck Personality Questionnaire-Revised (EPQ: Eysenck \& Eysenck, 1996) was used to obtain 
a measure of this predisposition. The EPQ requires participants to answer "yes" or "no" to 12 questions (e.g., “Are your feelings easily hurt?”). Responses are scored one for "yes" and zero for "no", giving a possible range of 0-12, with higher scores indicating a lower level of neuroticism. Sound reliability and validity data are reported in the EPQ manual (Eysenck \& Eysenck).

Demographics: Participants recorded information on their age, gender, length of unemployment and whether or not they were the principal income earner in their household.

\section{Procedure}

The study was a cross-sectional survey design using a convenience sample of unemployed adults. All participants were utilising the national employment service at the time they were surveyed. There was no time limit to complete the survey, and participants were offered the chance to win a $\$ 100$ voucher as a "thank you" for participating.

\section{Results}

\section{Validity of study measures}

To test the construct validity of the scales used in the study, all 92 items $(\mathrm{GHQ}=12$ items; $\mathrm{TS}=8 ; \mathrm{SS}=8 ; \mathrm{CP}=8 ; \mathrm{ST}=8 ; \mathrm{AC}=8 ; \mathrm{FS}=8 ; \mathrm{BHS}=20 ; \mathrm{EPQ}=12$ ) were included in a principal axis factor analysis, using a direct oblimin rotation. The KaiserMeyer-Olkin Measure of Sampling Adequacy (.85) and Bartlett's Test of Sphericity $\left(\chi^{2}=\right.$ 15154.72, $d f=3741, p<.001)$ indicated the suitability of the data for factor analysis (Tabachnik \& Fidell, 1996). Initially, nine factors were rotated (to reflect the nine scales 
included), however, this solution was factorially complex and not interpretable. The scree plot indicated that 10 factors should be rotated. When this was done, and four EPQ (Qs 2, 5, 7, 11, which cross-loaded on GHQ) and one BHS items (Qs 4, which did not load substantially on any factor) were removed, 10 interpretable factors remained. These ten factors encompassed the GHQ (12 items), TS (8), SS (8), CP (8), ST (8), AC (8), FS (8), EPQ (8) and two factors instead of one for BHS (10 and 9 items). All 10 factors had eigenvalues greater than one, and the solution accounted for $58.80 \%$ of the variance. There were no cross-loadings, no items with nil loadings, and all items loaded on the appropriate factors. The first BHS factor (Qs 2, 7, 9, 11, 12, 14, 16-18, 20) reflected negative future expectancies, and was labeled Negative Future Perspective (NFP). The second BHS factor (Qs 1, 3, 5, 6, 8, 10, 13, 15, 19) reflected positive future expectancies, and was labeled Positive Future Perspective (PFP). Summary data based on these factor analyses are reported in Table 1.

From the correlation matrix, meaningful associations $(r \geq .32$; Tabachnik \& Fidell, 1996) were found between Psychological Distress (GHQ) and Social Support (LAMBSS), Collective Purpose (LAMB-CP), Financial Strain (LAMB-FS), Negative Future Perspective (NFP), Positive Future Perspective (PFP) and Neuroticism (EPQ), such that high levels of distress were associated with low levels of social support, collective purpose, positive future perspective and neuroticism, and high levels of financial strain and negative future perspective. Social Support was further associated positively with Collective Purpose and Status (LAMB-ST), and negatively with Financial Strain and Negative Future Perspective. Collective Purpose was further associated positively with Status, and negatively with Financial Strain. Activity (LAMB-AC) was positively 
associated with Status. Lastly, Negative Future Perspective was negatively associated with Positive Future Perspective and Neuroticism. This analysis indicated that well-being was positively associated with access to the latent benefits of employment, with Psychological Distress being meaningfully associated with Social Support and Collective Purpose. Associations between Psychological Distress and Time Structure, Activity and Status were in the expected direction, but were weaker, accounting for $<10 \%$ of the variance in each correlation. This analysis also indicated that well-being was positively associated with access to the manifest benefits of employment and future orientation, with Psychological Distress being meaningfully and positively associated with Financial Strain and Negative Future Perspective, and negatively associated with Positive Future Perspective. 
Table 1

Summary data, internal reliability coefficients and bivariate correlations for variables of Psychological Distress, Time Structure, Social Support, Collective Purpose, Status, Activity, Financial Strain, Negative Future Perspective, Positive Future Perspective, Neuroticism, Age, Gender, Length of Unemployment and Principal Income Earner status; $N=239$

\begin{tabular}{|c|c|c|c|c|c|c|c|c|c|c|c|c|c|c|c|c|c|}
\hline Variable & $M$ & $S D$ & $\alpha$ & $1^{1}$ & 2 & 3 & 4 & 5 & 6 & 7 & 8 & 9 & 10 & 11 & 12 & 13 & 14 \\
\hline 1. GHQ & 14.61 & 7.59 & .92 & - & $-.14 *$ & $-.35 * * *$ & $-.32 * * *$ & $-.21 * *$ & -.11 & $.38 * * *$ & $.53 * * *$ & $-.40 * * *$ & $-.48 * * *$ & $=.18 * *$ & .08 & .08 & $.23 * * *$ \\
\hline 2. LAMB-TS & 33.46 & 9.02 & .90 & & - & -.02 & .12 & $.20 * *$ & $.13 *$ & -.04 & $-.16^{*}$ & .09 & .11 & .08 & .06 & .05 & .01 \\
\hline 3. LAMB-SS & 34.84 & 13.23 & .94 & & & - & $.55 * * *$ & $.21 * *$ & $.37 * * *$ & $-.32 * * *$ & $-.38 * * *$ & $.29 * * *$ & $.25 * * *$ & $-.16^{*}$ & -.06 & $-.18 * *$ & .03 \\
\hline 4. LAMB-CP & 31.14 & 12.48 & .93 & & & & - & $.32 * * *$ & $.29 * * *$ & $-.35 * * *$ & $-.24 * * *$ & $.19 * *$ & $.16^{*}$ & .03 & -.08 & -.05 & .06 \\
\hline 5. LAMB-AC & 39.42 & 10.48 & .89 & & & & & - & $.60 * * *$ & -.04 & $-.30 * * *$ & $.21 * *$ & $.18 * *$ & -.01 & .09 & $-.18 * *$ & -.01 \\
\hline 6. LAMB-ST & 43.07 & 11.00 & .93 & & & & & & - & .12 & $-.28 * * *$ & $.22 * *$ & .07 & $-.17 * *$ & .10 & $-.25 * * *$ & -.06 \\
\hline 7. LAMB-FS & 41.57 & 12.59 & .94 & & & & & & & - & $.20 * *$ & $-.17 * *$ & $-.21 * *$ & $.23 * * *$ & .03 & $.21 * *$ & .08 \\
\hline 8. NFP & 17.28 & 2.80 & .84 & & & & & & & & - & $-.53 * * *$ & $-.45 * * *$ & $.17 *$ & .01 & $.23 * * *$ & $.14 *$ \\
\hline 9. PFP & 11.08 & 2.07 & .73 & & & & & & & & & - & $.29 * * *$ & -.03 & .05 & $-.23 * * *$ & -.09 \\
\hline 10. EPQ & 12.83 & 2.29 & .75 & & & & & & & & & & - & .01 & -.08 & -.12 & -.08 \\
\hline 11. Age & - & - & & & & & & & & & & & & - & -.07 & $.16^{*}$ & $.31 * * *$ \\
\hline 12. Gender & - & - & & & & & & & & & & & & & - & -.03 & -.09 \\
\hline 13. UE & - & - & & & & & & & & & & & & & & - & -.05 \\
\hline 14. PIE & - & - & & & & & & & & & & & & & & & - \\
\hline
\end{tabular}

Note 1: GHQ = 12-item General Health Questionnaire; LAMB-TS = Time Structure subscale from Latent and Manifest Benefits of Employment Scale; LAMB$\mathrm{SS}=$ Social Support subscale from LAMB; LAMB-CP = Collective Purpose subscale from LAMB; LAMB-ST = Status subscale from LAMB; LAMB-AC = Activity subscale from LAMB; LAMB-FS = Financial Strain subscale from LAMB; NFP = 10-item Negative Future Perspective factor from Beck Hopelessness Scale; PFP = 9-item Positive Future Perspective factor from Beck Hopelessness Scale; EPQ = 8-item factor from Neuroticism subscale of Eysenck Personality Questionnaire - Revised; UE = continuous variable Length of Unemployment; PIE = dichotomous variable of whether participant was a Principal Income Earner or not.

Note 2: ${ }^{1}=$ Due to skewed distributions, all analyses using the following variables utilised transformed scores: LAMB-ST (Log10), NFP (Reflect and Square Root), PFP (Inverse), Age ( $\log 10)$ and UE $(\log 10)$.

Note 3: $*=p<.05, * *=p<.01, * * *=p<.001$. 


\section{Predicting Psychological Distress}

A standard multiple regression analysis was used to test the respective contributions of the latent benefits of employment, manifest benefits of employment and perceived future orientation in predicting psychological well-being. In this analysis, Psychological Distress (GHQ) was utilized as the dependent variable. The main independent variables of interest were the latent benefits of employment (Time Structure, Social Support, Collective Purpose, Activity and Status), the manifest benefit of employment (Financial Strain) and future focus (Negative Future Perspective and Positive Future Perspective). Neuroticism was included as an independent variable as this personality variable has been shown to influence the measurement of well-being. The variables of Age, Gender, Length of Unemployment and whether the participant was the Principal Income Earner (PIE) or not were controlled for by including as independent variables. Dummy variables were created for Gender (base $=$ females) and the Principal Income Earner variable $($ base $=$ not the principal income earner). Three interaction terms were also included to test whether the manifest benefit of employment interacted with perceived future orientation to influence well-being. These interaction terms included two two-way interactions, Financial Strain $\mathrm{x}$ Negative Future Perspective and Financial Strain x Positive Future Perspective, representing the interaction between Financial Strain and Negative and Positive Future Perspectives respectively, and one three-way interaction, Financial Strain $\mathrm{x}$ Negative Future Perspective $\mathrm{x}$ Positive Future Perspective, representing the interaction between Financial Strain and the two future perspectives. To avoid difficulties with multicollinearity, the interaction terms were calculated utilizing a centred score approach using a deviation from the mean transformation (Tabachnik \& Fidell, 1996). Summary 
data, including the semi-partial regression coefficients for each predictor variable, which are the contributions of individual predictor variables to the dependent variable after the other predictor variables have been statistically controlled, are included in Table 2.

The results of this analysis show that together the variables account for a significant $49 \%$ of the variance in Psychological Distress, $F(16,222)=423.98, p<.001$. The most important predictors of Psychological Distress, in order of importance, were Neuroticism $(\beta=-.25$; contributing a significant unique $4.58 \%$ of the variance; $p<.001)$, Negative Future Perspective $(\beta=.26 ; 3.57 \% ; p<.001)$, Financial Strain $(\beta=.21 ; 2.34 \% ; p=.002)$, Positive Future Perspective $(\beta=-.15 ; 1.42 \% ; p=.013)$, being a Principal Income Earner $(\beta=.12 ; 1.23 \% ; p=.021)$ and Length of Unemployment $(\beta=-.11 ; .09 \% ; p=.047)$. Predictor variables of Time Structure, Social Support, Collective Purpose, Activity, Status, Age, Gender and the two two-way and one three-way interaction terms, while contributing to explaining the overall variance, were not significant individual predictors. 
Table 2

Summary of Multiple Regression Analysis for variables predicting Psychological Distress; $N=239$.

\begin{tabular}{lrrrr}
\hline & & & & \\
Variable & $B$ & $S E B$ & $\beta$ & Semi-partial \\
& & & & \\
\hline LAMB-TS & -0.04 & 0.04 & -0.05 & -0.05 \\
LAMB-SS & -0.04 & 0.04 & -0.06 & -0.05 \\
LAMB-CP & -0.07 & 0.04 & -0.12 & -0.09 \\
LAMB-AC & -0.04 & 0.05 & -0.06 & -0.04 \\
LAMB-ST & 3.11 & 3.70 & 0.06 & 0.04 \\
LAMB-FS & 0.13 & 0.04 & $0.21^{* *}$ & 0.15 \\
NFP & 2.77 & 0.70 & $0.26^{* * *}$ & 0.19 \\
PFP & -73.44 & 29.44 & $-0.15^{*}$ & -0.12 \\
EPQ & -0.82 & 0.18 & $-0.25^{* * *}$ & -0.21 \\
Age & 4.93 & 2.81 & 0.10 & 0.08 \\
Gender & 0.87 & 0.75 & 0.06 & 0.06 \\
UE & -1.32 & 0.66 & $-0.11^{*}$ & -0.10 \\
PIE & 1.84 & 0.80 & $0.12^{*}$ & 0.11 \\
LAMB-FS x NFP & -0.01 & 0.05 & -0.01 & -0.01 \\
LAMB-FS x PFP & 0.59 & 2.18 & 0.02 & 0.01 \\
LAMB-FS x NFP x PFP & 3.24 & 2.31 & 0.08 & 0.07 \\
& & & &
\end{tabular}

Note 1: Refer to Table 1 for legend; LAMB-FS x NFP = Interaction term between Financial Strain and Negative Future Perspective; LAMB-FS x PFP $=$ Interaction term between Financial Strain and Positive Future Perspective; LAMB-FS $\mathrm{x}$ NFP $\mathrm{x}$ PFP = Interaction term between Financial Strain, Negative Future Perspective and Positive Future Perspective.

Note $2: *=p<.05 ; * *=p<.01 ; * * *=p<.001$

Note 3: $R^{2}=0.49$; Adjusted $R^{2}=0.46$. 


\section{Path Analysis}

A path analysis was conducted to test whether perceived future orientation acts as a mediating variable between financial strain and well-being. While path analysis does not set out to prove causality among a set of variables it is able to investigate how tenable a particular model is. It is the analysis of choice in this particular study, as the sample size did not allow for more complex analyses, such as structural equation modeling. The model reported in Figure 1 is an abbreviated version of the full model tested. Figure 1 has been reduced by not including the variables that failed to generate a significant pathway. The full model, reported in Table 3, proposed that the manifest benefits of employment (Financial Strain), the latent benefits of employment (Time Structure, Social Support, Collective Purpose, Activity, Status), Neuroticism, Age, Gender, Length of Unemployment, and whether the participant was the Principal Income Earner or not, would influence Psychological Distress via Negative Future Perspective and Positive Future Perspective. The interaction terms were not included in the path analysis as they failed to contribute significant individual variance to the prediction of Psychological Distress (Table 2) and could not be used to predict Negative or Positive Future Perspective. The path analysis involved performing separate multiple regression equations for each endogenous variable in the model and calculating the total effects for the predictor variables (based on direct and indirect effects) on Psychological Distress. Endogenous variables are those variables that are preceded by predictor variables. Indirect effects are calculated by multiplying the beta weights from paths that connect a predictor variable to its designated dependent variable. When more than one path exists between a predictor and its dependent variable, the products of the beta weights are 
summed to produce the total effect of one variable on another. The standardised regression coefficients of the predictor variables and their endogenous (dependent) variables are displayed as path coefficients (beta weights) in Figure 1.

The results indicate that $49 \%$ of the variance of Psychological Distress was accounted for by the predictor variables. Negative Future Perspective, Positive Future Perspective, Financial Strain, Neuroticism and whether the participant was the Principal Income Earner or not were significant individual predictors. Neuroticism had the strongest total effect (direct effect plus indirect effect) on Psychological Distress (with $\beta=-.61$ ), followed by Financial Strain $(\beta=.36)$, being a Principal Income Earner $(\beta=.30)$ and Negative Future Perspective $(\beta=.26)$. Neuroticism had the strongest effect on Negative Future Perspective $(\beta=-.33)$, followed by Social Support $(\beta=.30)$ and Length of Unemployment. Neuroticism also had the strongest effect on Positive Future Perspective $(\beta=.20)$, followed by Social Support $(\beta=.18)$. The findings suggest that Psychological Distress is primarily determined directly by Neuroticism, Financial Strain and Negative Future Perspective, with minor direct roles for Positive Future Perspective, and being a Principal Income Earner. Neuroticism, Social Support and Length of Unemployment also have indirect effects through Negative Future Perspective, and Neuroticism and Social Support have an indirect effect through Positive Future Perspective. Financial Strain influences Psychological Distress directly, and not through Negative Future Perspective or Positive Future Perspective as hypothesized. 


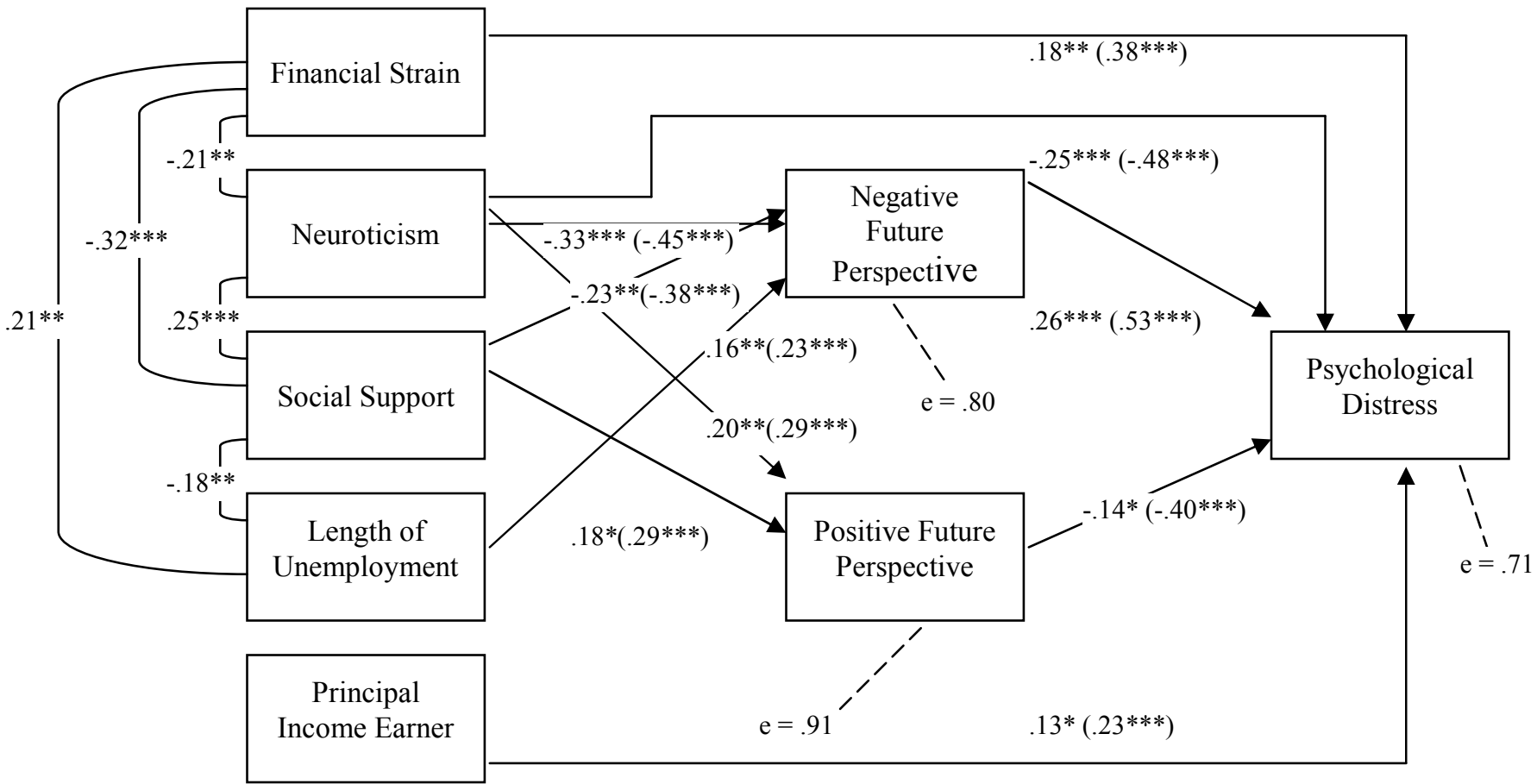

Figure 1: The effect of Negative Future Perspective, Positive Future Perspective, Manifest Benefits, Latent Benefits (Time Structure, Social Support, Collective Purpose, Activity, Status), Neuroticism, Age, Gender, Length of Unemployment and whether the participant was the Principal Income Earner or not on Psychological Distress. For pathways indicated with an arrow, standardised regression coefficients are presented without brackets, bivariate correlations are presented within brackets; bivariate correlations are represented by curved lines. $*=p<.05 ; * *=p<.01 ; * * *=p<.001$ 
Table 3

Direct and indirect effects for predicting Psychological Distress using Negative Future Perspective, Positive Future Perspective, Manifest Benefits, Latent Benefits (Time Structure, Social Support, Collective Purpose, Activity, Status), Neuroticism, Age, Gender, Length of Unemployment and whether the participant was the Principal Income Earner or not; $N=239$.

Dependent Variables

\begin{tabular}{|c|c|c|c|c|c|c|c|c|}
\hline \multirow[b]{2}{*}{$\begin{array}{l}\text { Predictor } \\
\text { variables }\end{array}$} & \multicolumn{4}{|c|}{ GHQ } & \multicolumn{2}{|c|}{ NFP } & \multicolumn{2}{|c|}{ PFP } \\
\hline & $\begin{array}{l}\text { Direct } \\
\text { effects }\end{array}$ & $\begin{array}{l}\text { Indirect } \\
\text { effects }\end{array}$ & $\begin{array}{l}\text { Total } \\
\text { effects }\end{array}$ & $R^{2}$ & $\begin{array}{l}\text { Total } \\
\text { effects }\end{array}$ & $R^{2}$ & $\begin{array}{l}\text { Total } \\
\text { effects }\end{array}$ & $R^{2}$ \\
\hline NFP & $.26^{* * *}$ & - & .26 & $.49 * * *$ & - & $.36 * * *$ & - & $.18 * * *$ \\
\hline PFP & $-.14^{*}$ & - & -.14 & & - & & - & \\
\hline LAMB-TS & -.05 & -.08 & -.13 & & -.10 & & .03 & \\
\hline LAMB-SS & -.05 & -.14 & -.19 & & $-.23 * *$ & & $.18^{*}$ & \\
\hline LAMB-CP & -.12 & -.12 & -.24 & & .00 & & -.02 & \\
\hline LAMB-AC & -.05 & -.10 & -.15 & & -.15 & & .07 & \\
\hline LAMB-ST & .06 & .05 & .11 & & -.01 & & .08 & \\
\hline LAMB-FS & $.21 * *$ & .18 & .36 & & -.03 & & -.07 & \\
\hline EPQ & $-.25 * * *$ & -.36 & -.61 & & $-.33 * * *$ & & $.20 * *$ & \\
\hline Age & .10 & .11 & .21 & & .07 & & .07 & \\
\hline Gender & .05 & .05 & .10 & & .03 & & .05 & \\
\hline UE & -.11 & -.05 & -.16 & & $.16^{* *}$ & & -.11 & \\
\hline PIE & $.13^{*}$ & .17 & .30 & & .11 & & -.09 & \\
\hline
\end{tabular}

Note: See Table 1 for legend; $*=p<.05 ; * *=p<.01 ; * * *=p<.001$

\section{Discussion}

Consistent with previous findings (e.g., Creed \& Macintyre, 2001; Jackson, 1999), the latent benefits of employment were associated with psychological well-being in this sample of unemployed people. When the other variables were controlled for, the most important latent benefits associated with distress were Collective Purpose and Social 
Support (see Table 3), although much of their effect was indirect, acting to reduce Negative Future Perspective and increase Positive Future Perspective. This evidence is partial support for Jahoda's (1981) Latent Deprivation Model, although it does not support Jahoda's (1982) contention that Time Structure was the most important latent benefit. Unemployed people who reported being a part of a collective purpose and who reported higher levels of social support did have lower levels of psychological distress. Other studies have identified different latent benefits as having important associations with distress in unemployed samples (e.g., Creed \& Macintyre; Creed \& Watson, In press), so it is likely that different unemployed people, perhaps in different stages of their unemployment cycle or in different situations are distressed by the deprivation of different latent benefits. It is possible, for example, that the stigma of unemployment and losing a time regime may be more salient in the early stages of unemployment, whereas social support may be more salient as unemployment continues. There is some support for propositions like this from studies that have interviewed unemployed people at different stages of being unemployed (cf. Hill, 1977), but they will need to be tested using longitudinal designs.

In contrast to the latent benefits, the manifest benefit of employment, operationalised in this study as Financial Strain, emerged as a more important variable, with clear, direct associations with distress. This evidence is not consistent with Jahoda's proposition that deprivation of the latent benefits of employment would have more of an impact than deprivation of the manifest benefits of employment. This strong association between perceived economic deprivation and distress is consistent with other studies (e.g., Whelan, 1992), and is more in line with Fryer's (1986) explanation for the deteriorating 
well-being associated with unemployment. In this study, unemployed people who reported high levels of Financial Strain, also reported more Psychological Distress. Also consistent with Fryer's account, was the significant association between the perception of the future and psychological distress. Participants with a higher Negative Future Perspective and a lower Positive Future Perspective reported more distress. Both economic deprivation and perception of the future were meaningfully associated with well-being, and explained unique variance when predicting psychological well-being. This is strong support for the Agency Restriction Model, as both variables were predicted by Fryer to contribute to the deterioration in well-being of unemployed people.

Financial Strain and Negative or Positive Future Perspective did not interact to predict Psychological Distress. This indicates that economic deprivation and perception of the future operate independently to predict well-being, and that perception of the future does not moderate the impact of economic deprivation on well-being, or vice versa. Also, Financial Strain did not predict Negative Future Perspective or Positive Future Perspective, which indicates that well-being is influenced by economic deprivation directly but not through the perception of the future. Fryer's argument that economic deprivation and a negative future orientation "coalesce" (1995, p. 271) and that poverty affects well-being directly as well as by influencing the view of the future are not supported. Economic deprivation and a negative future orientation can best be viewed as summative rather than having a moderating or mediating relationship. This is an important finding. It has implications for training and counselling for unemployed people, where reducing negative views of the future might reduce psychological distress, even though financial situations remain unchanged. Conversely, it has implications for 
public policy, where improving the economic situation of unemployed people might be expected to reduce distress, but would not necessarily change a negative view of the future.

As in previous studies (e.g., Creed, Muller \& Machin, 2001; Payne, 1988), Neuroticism was found to be strongly associated with Psychological Distress. This means that unemployed people who see the world as more threatening and worrying are more likely to be distressed. Neuroticism, however, is more pervasive than presented in this picture. In this study, those with higher levels of neuroticism also had a more Negative and less Positive Future Perspective, which in turn increased distress; and those with higher levels of neuroticism also reported more Financial Strain and less Social Support. This implies that Jahoda's situational perspective and Fryer's agency explanation of distress in unemployed people, while accounting for meaningful proportions of the variance, do need to incorporate temperament in their explanation. Neuroticism has been found to be strongly associated with distress in unemployed populations, however, other personality variables have yet to be examined (though see Creed, 1999; Creed \& Evans, In press). In other studies (for a review, see Diener, Suh, Lucas, \& Smith; 1999), other personality constructs have been shown to be associated with well-being, and temperament needs to be incorporated in any explanatory model of distress in the unemployed. For example, of the big five personality variables (McCrae \& Costa, 1991), being more outgoing (Extraversion) and having less of a commitment to be employed (Conscientiousness) may be protective factors for unemployed people; while being more flexible in the types of jobs considered (Openness) might be advantageous when returning to the workplace. 
In relation to Social Support, the results of this study are inconsistent with previous research that has identified a direct relationship between social support and well-being (e.g., Haworth \& Ducker, 1991; Jackson, 1999). However, the results are consistent with other studies that have examined all of the latent and manifest benefits of employment together, and which have not identified social support as moderating the negative effects of unemployment (e.g., Creed \& Macintyre, 2001). The most likely explanation for this is that when a comprehensive range of variables is measured the direct effects of social support on well-being are reduced. But, as is the case in the present study, the effects of social support can be mediated through these other variables, in this instance, mediated through the individual's view of the future. Social support has been implicated in stress research in the occupational field generally (e.g., see Karasek, \& Theorel, 1990), and can be accepted as an important moderating variable in relation to unemployed people. However, as this study has shown, social support was influential as it operated to influence another variable (future orientation), which in turn had the effect of reducing the distress associated with unemployment.

Two other variables were shown to have significant effects on Psychological Distress. The first of these, being a Principal Income Earner, had a direct effect on increasing distress. The unemployed who viewed themselves as performing this role fared poorer than their non-Principal Income Earner counterparts. Researchers utilizing role theory (Stryker, 1980) have stressed the importance of the ability to provide for oneself, partner and/or family, and the reason that failure to do so may be distressing for the individual. Scanzoni (1978), for example, described the provider role as a "sacred duty" (cited in Bernard, 1981, p. 125), and Wiley (1991) indicated that traditional family 
responsibilities are not fulfilled when people cannot provide for their family. Results from the present study are consistent with this notion, that those who identified with this responsibility were more distressed when their role as provider is frustrated. Wiley also linked the absence of a job with the inability to meet the provider role in the family, implying a link between this role and financial strain. This was not identified in the present study. Being a Principal Income Earner was associated with higher levels of distress, but it was not associated with more Financial Strain (nor was it associated with the individual's view of the future), indicating some other pathway between role and distress apart from through a financial one. Examining family responsibilities in unemployed people is likely to be a fruitful avenue of research, which might help account for some of the inconsistencies identified in the area.

The final variable to produce an effect on well-being was Length of Unemployment. This effect was indirect, with Length of Unemployment operating to increase the individual's negative view of the future, which in turn increased Psychological Distress. Length of unemployment has been identified as a moderating variable by some authors who have suggested a curvilinear relationship, with negative experiences being more pronounced early on, and improving as individuals become more adjusted to their situation (Warr \& Jackson, 1987). The picture remains unclear, however, as at least some groups of unemployed continue to deteriorate in well-being as they experience more prolonged unemployment (Creed \& Poulton, 1999; Winefield \& Tiggemann, 1989; 1990). Further complicating the issue is that unemployment length is problematic to measure (see Creed \& Watson, In press). Indications of length of unemployment can be unreliable, being influenced by such factors as the previous reference job used, faulty or 
socially desirable estimations when the unemployment period is of a long duration, and the influence of breaks such as holidays or incapacity for work that affect the overall estimation. The useful evidence from this study is that length of unemployment may operate in an indirect manner and may be an important variable, even when no direct association with well-being is found.

In summary, Financial Strain and future orientation, the two main variables in Fryer's Agency Restriction Model, were the most important predictors of Psychological Distress, after the personality variable of Neuroticism. No interaction effect between Financial Strain and future orientation was identified, and future orientation did not mediate the influence of Financial Strain. The contextual variable of the unemployed person being a Principal Income Earner, which can be construed as representing one of Jahoda's Latent Deprivation Model variable, that of Status, influenced Psychological Distress directly; whereas Social Support, a second Latent Deprivation Model variable, influenced distress indirectly via Negative and Positive Future Perspective. This evidence suggests that examining internal personal agency processes (in this instance, the cognitive variables of future orientation and perceived financial strain) in the context of the individual's temperament and situation, may be a more fruitful way of explaining the decline in wellbeing associated with unemployment than relying on either one or the other of the two models tested in this study. At a practical level, the evidence also suggests that interventions for the unemployed might also include planning and financial education strategies, such as budgeting, financial management and clever purchasing. 


\section{References}

Australian Bureau of Statistics (2003). Labour Force, Australia. Catalogue 6202.0. Canberra: ABS.

Banaji, M. R., \& Prentice, D. A. (1994). The self in social contexts. Annual Review of Psycholgy, 45, 297-332.

Batson, C. D., \& Ventis, W. L. (1982). The religious experience. New York: Oxford University Press.

Beck, A.T., Weissman, A., Lester, D., \& Trexler, L.(1974). The measurement of pessimism: the hopelessness scale. Journal of Consulting and Clinical Psychology, 42, $861-865$.

Bernard, J. (1981). The good provider role: Its rise and fall. American Psychologist, $36,1-12$.

Bolton, W., \& Oatley, K. (1987). A longitudinal study of social support and depression in unemployed men. Psychological Medicine, 17, 453-460.

Cantor, N., \& Fleeson, W. (1991). Life tasks and self-regulatory processes. Advances in Motivation and Achievement, 7, 327-69.

Creed, P. A. (1999). Personality characteristics in unemployed Australian males Implications for "drift" hypothesis in unemployment. Psychological Reports, 84, 477480.

Creed, P. A., \& Bartrum, D. (Submitted). Testing the latent and manifest benefits of employment as demands in the control-demand model with an unemployed sample. 
Creed, P. A., \& Evans, B. (In press). Personality, wellbeing and deprivation theory. Personality and Individual Differences.

Creed, P. A., \& Macintyre, S. R. ( 2001). The relative effects of derivation of the latent and manifest benefits of employment on the well-being of unemployed people. Journal of Occupational Health Psychology.

Creed, P. A., \& Muller, J. (Submitted). Predicting psychological distress across occupational settings: Shame or deprivation.

Creed, P. A. \& Poulton, M. (1999). Ability levels, mental health and attitudes-to-work of the chronic unemployed. South Pacific Journal of Psychology, 10(2), 1-14.

Creed, P.A., Muller, J., \& Machin, M. A. (2001). The role of satisfaction with occupational status, neuroticism, financial strain and categories of experience in reducing mental health in the unemployed. Journal of Personality and Individual Differences, 30, 435-447.

Creed, P. A., \& Watson, T. (In press). Age, gender, psychological well-being and the impact of losing the latent and manifest benefits of employment in unemployed people. Australian Journal of Psychology.

Diener, E., Suh, E., Lucas, R., \& Smith, H. (1999). Subjective well-being: Three decades of progress. Psychological Bulletin, 125(2), 276-302.

Dawkins, P. (1996). The distribution of work in Australia. Paper presented at the Inaugural Lecture by Professor Peter Dawkins, Institute of Applied Economic and Social Research, Melbourne University.

Eysenck, H. J., \& Eysenck, S. B. G. (1996). Manual Of Eysenck Personality Scales (EPS-Adult). London: Hoder \& Stoughton Educational. 
Evans, S. T., \& Haworth, J. T. (1991). Variations in personal activity, access to categories of experience and psychological well-being in unemployed young adults. Leisure Studies, 10, 249-264.

Feather, N. T. (1990). The psychological impact of unemployment. New York, Springer-Verlag.

Fryer, D. M (1986). Employment deprivation and personal agency during unemployment: A critical discussion of Jahoda's explanation of the psychological effects of unemployment. Social Behaviour, 1, 3-23.

Fryer, D. M. (1995). Labour market disadvantage, deprivation and mental health benefit agency. The Psychologist, 6, 265-272.

Fryer, D. \& McKenna, S. P. (1987). ' The laying off of hands: unemployment and the experience of times', in S. Fineman (Ed.), Unemployment and the Experience of Time: Personal and social consequences. London: Tavistock.

Fryer, D. \& Payne, R. (1986). Being unemployed: A review of the literature on the psychological experience of unemployment. In C. L. Cooper \& I. Robertson (Eds.). International Review of Industrial and Organizational Psychology (pp. 235-278). Chichester: John Wiley.

Goldberg, D. P. (1972). The detection of psychiatric illness by questionnaire. London: Oxford University Press.

Goldberg, D. P., \& Williams, P. (1988). A users guide to the General Health Questionnaire. Berkshire: NFER- NELSON.

Greene, S. M. (1981). Levels of measured hopelessness in general population. British Journal of Clinical Psychology, 20, 11-14. 
Hawkins, W.E., Hawkin, M., Sabatino, C., \& Ley, S. (1998). Relationship of perceived future opportunity to depressive symptomatology of inner city African American adolescents. Children's and Youth Services Review, 20, 9-10.

Haworth, J. T., \& Ducker, J. (1991). Psychological well-being and access to categories of experience in unemployed young adults. Leisure studies, 10, 265-274.

Hill, J. M. (1977). The social and psychological impact of unemployment. London: Tavistock.

Hellstrom, C., Jansson, B., \& Carlsson, S. G. (2000). Perceived future in chronic pain: The relationship between outlook on future and empirical derived psychological patient profiles. European Journal of Pain, 4(3), 283-90.

Jackson, T. (1999). Differences in psychosocial experiences of employed, unemployed, and student samples of young adults. Journal of Psychology, 133, 49-60.

Jahoda, M. (1981). Work, employment, and unemployment: Values, theories and approaches in social research. American Psychologist, 36(2), 184-191.

Jahoda, M. (1982). Employment and unemployment: a social-psychological analysis. Cambridge University Press, Cambridge.

Jahoda, M. (1984). Social institutions and human needs: A comment on Fryer and Payne. Leisure Studies, 3, 297-299.

Karasek, R., Theorell, T. (1990). Healthy work: Stress, productivity, and the reconstruction of working life. New York: Basic Books.

Kokko, K., \& Pulkkinen, L. (1997). Economical and psychological well-being of the unemployed. Psykologia, 32, 349-359. 
Milne, S. \& Ryle, S. (1996). World's jobless total I billion. The Guardian, Tuesday November 26.

McCabe, K., \& Barnett, D. (2000). First comes work then comes marriage: Future orientation among African American young adolescents. Family Relations, 49(1), 63-70.

McCrae, R. R., \& Costa, P. T. (1991). Adding liebe und arbeit: The full five factor model of well-being. Personality and Social Psychology Bulletin, 17, 227-232.

Muller, J., Creed, P. A., Waters, L., \& Machin, M. A. (2000). A new scale to measure functions of unemployment. Paper presented at $27^{\text {th }}$ International Congress of Psychology, 23-28 July, 2000, Stockholm, Sweden.

Muller, J., Hicks, R., \& Winocur, S. (1993). The effects of employment and unemployment on psychological well-being in Australian clerical workers: Gender differences. Australian Journal of Psychology, 45(3), 103-108.

Murphy, G. C, \& Athanasou, J. (1999). The effects of unemployment on mental health. Journal of Occupational and Organisational Psychology, 72, 83-100.

Nuri, J. E. (1991). How do adolescents see their future? A review of the development of future orientation and planning. Developmental Review, 11, 1-59.

Payne, R. (1988). A longitudinal study of the psychological well-being of unemployed men and the mediating effect of neuroticism. Human Relations, 41, 119-138.

Seginer, R. (2000). Defensive pessimism and optimism correlates of adolescent future orientation: A domain-specific analysis. Journal of Adolescent Psychology, 15(3), 307326.

Spiers, R. (1991, Monday, 11th March). Growing problem of long-term unemployed. Financial Review, p. 6. Sydney: John Fairfax Group. 
Steed, L. (2001). Further validity and reliability for Beck Hopelessness Scale scores in a nonclinical sample. Educational and Psychological Measurement, 61(2), 303-316.

Tabachnick, B.G., \& Fidell, L. S. (2001). Using multivariate statistics. Allyn \& Bacon: Boston.

Stryker, S. (1980). Symbolic interactionism: A social structural version. Palo Alto: Benjamin/Cummings.

Underlid, K. (1996). Activity during unemployment and mental health. Scandinavian Journal of Psychology, 37, 269-281.

Viinamaki, H., Koskela, K., Niskanen, L., Arnkill, R., \& Tikkanen, J. (1993). Unemployment and mental well-being: A factory closure study in Finland. Acta Psychiatrica Scandinavia, 88, 429-433.

Warr, P. B., \& Jackson, P. R. (1987). Adapting to the unemployed role: A longitudinal investigation. Social Science and Medicine, 25, 1219-1224.

Waters, L. E., \& Moore, K. A. (2002). Reducing latent deprivation during unemployment: The role of meaningful leisure activity. Journal of Occupational and Organisational Psychology, 75, $15-32$.

Whelan, C. T. (1992). The role of income, life style deprivation and financial strain in mediating the impact of unemployment on psychological distress: Evidence from the Republic of Ireland. Journal of Occupational and Organizational Psychology, 65, 331344.

Wiley, M. G. (1991). Gender, work, and stress: The potential impact of role-identity salience and commitment. The Sociological Quarterly, 32(4), 495-510. 
Winefield, A. H., \& Tiggemann, M. (1989). Unemployment duration and affective well-being in the young. Journal of Occupational Psychology, 62, 327-336.

Winefield, A. H., Tiggemann, M., Winefield, H. R., \& Goldney, R. D. (1993). Growing up with unemployment: a longitudinal study of its psychological impact. London: Routedge. 